\title{
Pervasive Pollution Problems Caused by Plastics and its Degradation
}

\author{
https://doi.org/10.3991/ijoe.v15i10.10873 \\ Sidra Hassan( ${ }^{\varpi)}$, Ihsan ul Haq \\ National Agricultural Research Centre (NARC), Islamabad, Pakistan \\ sadra celal@hotmail.com
}

\begin{abstract}
We are living in a period of time where gaining access to clean water, food and even air is almost impossible. Everything on the planet Earth is contaminated in one form or another. Not only humans but all the creatures of the planet are under constant threat from atleast one of the forms of pollution. Like other forms of pollution, plastic pollution is also a huge and mounting problem and it demands a similarly ambitious and influential solution. As 'human-caused climate change' received so much attention, this issue also needs the same consideration and it should be approached in the same way. Plastic pollution is killing our planet! It's choking our oceans by making plastic gyres, entangling marine animals, poisoning our food and water supply, and ultimately inflicting havoc on the health and well-being of humans and wildlife globally. With the exception of small amount that has been incinerate, virtually every piece of plastic that was ever made in the past still exists in one form or another. And since most of the plastics don't biodegrade in any meaningful sense, all that plastic waste could exist for hundreds or even thousands of years. If plastic production isn't circumscribed, plastic pollution will be disastrous and will eventually outweigh fish in oceans. It's time to think about the plastics, banning the single use plastics, thinking about the recycling and going towards the zerowaste concept. This paper covers the reviews about current research on the plastic disasters by plastic industry and biodegradation of the conventional synthetic plastics by different microorganisms and major concerns related to ocean plastic pollution.
\end{abstract}

Keywords-Plastic Pollution, Biodegradation, Wildlife, Contamination

\section{$1 \quad$ Introduction}

Plastics are man-made, polymeric molecules which are arranged in long chains [1]. The importance of plastics can be seen in everyday life as it has become a very crucial part of our living systems. It is not more than a half a century ago, when synthetic polymer started to substitute natural materials in almost every area. With the passage of time, the strength and durability of plastics have been upgraded uninterruptedly, and it resulted in improved quality of plastic which are resistant to many ecological influences. Hence this group of materials is now considered as a synonym for those materials which are inert and resistant to different environmental conditions. The 
word plastic is from the Greek word "plastikos", meaning 'ability to be shaped or molded into different forms/shapes' [2]. The plastics we use in everyday life are made from inorganic and organic raw materials, such as carbon, silicon, hydrogen, nitrogen, oxygen and chloride. Coal, natural gas and oil are used for the extraction of basic materials used for making plastics [3]. Nowadays, an extensive variety of petroleumbased synthetic polymers are produced worldwide to fulfill the needs of growing population. Approximately 140 million tons of plastics are made per year and remarkable amounts of these polymers find their way in the ecosystem as industrial waste products. A very great deal of plastics is used for packaging which comprises around $30 \%$ of the total plastics produced. This utilization is expanding at a rate of $12 \%$ per annum which is quite a high rate. Synthetic plastics are commonly used in packaging of products like food, drugs, cosmetics, chemicals and detergents. They have replaced paper and other cellulose-based products for packaging because of their better physical and chemical properties. Their resistance, light weight, non-degradable nature and strength makes them a better choice. Polyethylene (LDPE, MDPE, HDPE and LLDPE), polypropylene (PP), polystyrene (PS), polyvinyl chloride (PVC), polyurethane (PUR), polyethylene terephthalate (PET), poly butylene terephthalate (PBT) and nylons are the most widely used plastics for packaging. The widespread applications of plastics are not only due to their favorable mechanical and thermal properties but also mainly due to the stability and durability which are the vital factors to be considered. Major reason why plastics have attained more public and media attention is because of their robustness, durability and clear visibility in the litter as compared to other component of the solid waste stream.

In recent years it has been observed that the demand for resources increased tremendously with the increase in population and urbanization. In 1993, the global demand for plastics was over 107 million tones, which increased to around 146 million tons in 2000 [4]. Plastic is one of the dangerous elements among waste. Plastic and polymeric products are now being a part of our life and living without them is almost beyond thoughts. Plastic products got propagated and widely being accepted because of many reasons like light weight, attaining different shape/form, color diversity, noncorrosive in nature, saves the use of plant woods for house hold furniture and much more.

The applications of plastic are rapidly snowballing all over the world. Glance of their usages pattern in daily life indicates that we are approximately surrounded by $70-80 \%$ of plastics ranging from packaging materials, kitchenware, automobiles and children toys to the components of the designed products, the biomedical devices or aircrafts. Production of plastic has increased from 0.5 million tons in 1950 to 260 million tons in 2007. This increase in usage, especially throwaway items of packaging, makes $37 \%$ of all the products of plastic [5].

Plastics are used in a variety of other consumer and industrial products viz. fibers, textile, packaging, automobiles, paints, alternate building materials etc. Due to their multipurpose properties, plastics are also used in the electronics such as television, refrigerators, air conditioners, agricultures etc. The use of plastic medical devices in hospitals for the storage and transfusion of life saving fluids, syringes, blood bags, biomedical implantations, tubing and heart valves for the cardiac patients is of utmost 
importance. In the present scenario, 33\% of plastic is being used for the packaging purpose, building construction constitutes about $20 \%, 7 \%$ in automobiles, electrical and electronic items make $10 \%$, agriculture and other sectors constitutes $5 \%$ and $25 \%$ respectively. Plastic use is dominated by single use which has a very short life span, and at the same time most plastics are extremely persistent in the environment thus intensifying the situation [6].

\section{Disasters by Plastic Waste}

Plastics are one of the most persistent forms of pollutant that takes hundreds of years to degrade. Scientists around the world are increasingly discovering wildlife that has been killed after feasting on plastics or becoming entangled in plastic and choked to death. The literature on marine debris leaves no hesitation that plastics make-up most of the marine litter worldwide [7]. Approximately $90 \%$ of the birds have been found to have plastic in their stomachs. And the problem is only getting worse. These plastics will not only kill more wildlife; they'll also decimate coral reefs and will severely effect the marine ecosystem. Plastic effects on human health is another major concern that need utmost attention as microplastics enter the food chain, contaminates it and finds its way to human body. If production and use of plastics keeps increasing at this rate, it will soon create more and bigger dead zones where nothing would live, will harm biodiversity, and will change ecosystems. There will likely be other, unknown impacts; as researchers have only been studying ocean plastics for less than two decades.

The first ever report on marine environment pollution by plastics was documented about 50 years ago, less than two decades after the rise of marketable plastics production, when less than 50 million metric tons were produced annually. In all major marine habitats, plastic debris has been detected ranging from microns to meters. In response, concerns about risks to marine wildlife upon exposure to the varied forms of plastic debris have augmented and resulted in stimulating new research and consequences of plastics contamination in the marine environment. Despite remaining knowledge gaps in mass budgeting and challenges in investigating ecological impacts, the increasing evidence of the ubiquity of plastics contamination in the marine environment, the continued rapid growth in plastics production, and the indication - albeit limited - of demonstrated influences to marine wildlife support immediate execution of source-reducing measures to decrease the potential risks of plastics in the marine ecosystem [8].

The quantity of plastic waste from household have increased remarkably in recent decades [9]. Plastic waste treatment is becoming a global mission for the entire nations of the world due to its adverse effects on environment as well as marine life [10, 11]. In past, plastic waste has been degraded by concerned authorities within other waste in landfill which emerged an expensive method $[12,13]$. Its effects on environment are countless and are of serious concerns but following are of utmost importance to consider and resolve. 
There is still less information about the impact of plastics on marine ecosystem as it is the primary concern of plastic pollution $[14,15]$. However, with the passage of time there is increasing knowledge on harmful effects of plastic pollution on marine ecosystem [16). Since the use of plastic pollution has been increased with the investment of global population with the passage of time, that's why its threats to marine life also been increasing on same ratio([17]. A study in the North Pacific Ocean revealed that plastic particles has been found in stomachs of 8 out of 11 sea birds [18].

Plastic has adverse effects on marine organisms, especially microplastic having size less than $5 \mathrm{~mm}$, has been assessed. It has been concluded that microplastic may transferred toward the circulatory system [19]. Due to this, other organisms which rely on the marine life for food are also affected hence creating a primary effect on food chain $[20,21]$. Studies on marine mammals show that plastic particles shift towards food chain by consuming plastic effected fish [22]. Similarly, accumulation of larger plastic particles has been observed in ocean gyres, on beaches and in sediments throughout the world which effects marine life as well humans [23].

According to BBC, with the growth of world population, most of the marine species are threatened day-by-day due to the emergence of larger amount of plastic waste on bank of oceans and freshwater. Wildlife especially marine animals are on high risks as they become tangled in plastic or ingest it. One plastic bag can kill many species and it will still remain the same. Many evidences have come across showing the death of marine animals due to plastic. A whale was found dead in the coast of Philippine due to ingestion of $40 \mathrm{kgs}$ of plastic, which was found in his stomach [24].

There are many evidences regarding the death of marine animals in the oceans. Sea birds like gulls along with sea mammals such as seals, turtles, dolphins and whales get trapped in plastic bags and choked routinely. Fish ingest plastic bags and other micro plastic particles which are further consumed by human and other animals, have dangerous carcinogenic effect and hence effecting the food chain and environment constantly [25].

According to United Nation, $80 \%$ of oceanic pollution comes from land and it constitutes 8 million tons of plastic waste each year, and causes death to more than 1 million and 0.1 million of sea birds and sea mammals annually. Plastic pollution, apart from other dangerous pollutions, is damaging major part of marine resources of water world. Major increases in the fishing and tourism industry has been associated with the continuous disturbance of the marine species like turtles and birds, whales and dolphins, and finally entering to remote areas of the world and especially occupying the food chain.

In the ocean, where plastic cannot be easily removed, it gets accumulated in organisms and sediments, and persists much longer than on land. New evidence indicates a complex toxicology of plastic micro- and nanoparticles on marine life, resulting in food chain poisoning and ultimately effecting humans on land [26].

While turning towards the impact of plastic on human health there is a growing literature on its potential health risks [27]. A wide variety of chemicals that are used in manufacturing process of plastic are extensively harmful to human and may cause serious health threats i.e. reproductive abnormalities [28, 29]. Besides this, exposure to these chemicals may cause endocrine disruption and other damages to molecular 
system of the body [30]. It mainly exposes to human body through ingestion, inhalation and dermal contact $[31,32]$.

Report published in Guardian on October 22nd 2018, states that microplastics of 9 different types were found in stool sample of size ranging from 50-550 micrometers. Polypropylene and polyethylene terephthalate are mostly found plastics. Rough estimation by author indicates that more than $50 \%$ of the world population might have microplastics in their stools, though they stressed the need for larger-scale experiments to confirm this. "The smallest microplastic particles are capable of entering the bloodstream, the lymphatic system, and may even reach the liver," said Schwabl, who will further report on the study. As first evidence of microplastics presence inside humans are confirmed, we need further research to understand what this actually means for human health and future.

\section{Plastic Degradation}

In last few years a remarkable pressure on disposal of plastic waste has been observed on authorities. Some technological advancement has been made in biodegradation disposal of plastic as it is shown by many researchers that some type of plastic such as thermoplastic which is derived from polyolefins are biodegradable through photo degradation [33].

Any change, either physical or chemical can occur in polymer as a result of environmental influences, such as light, heat, moisture, chemical conditions or biological action. Polymer degradation can be defined as processes that induces changes in the physical, chemical or biological reactions resulting in breaking of bonds and subsequently results in chemical transformations. Degradation has been reflected in changes of material properties such as mechanical, optical or electrical characteristics, in crazing, cracking, erosion, discoloration, phase separation or delamination. The changes include bond scission, chemical alteration/transformations and formation of new functional groups [34].

As our environment and especially oceans are heavily polluted by plastics, so there emerges a need for its degradation. Conventional methods of polyethylene degradation includes incineration, landfill and chemical treatment. All such techniques are lethal to the neighboring environment by causing hazardous effects on living organisms. Incineration effect on the environment are more hazardous in a way that different gases are released into the atmosphere thus causing severe health concerns. Incineration involves heating plastic waste at a high temperature and thus degrading it. Approximately $11 \%$ of the plastic has been incinerated till date. This is a very small fraction as remaining huge portion still persists in the environment in one form or another.

\subsection{Plastic biodegradation}

Different polymers with high molecular weight combine to form a broad term named as plastic and it can be degraded by many processes but microbial degradation 
of plastic seems to be most effective process due to bioavailability and abundance of microorganisms and enzymes in the environment. For plastics, being utilized by microorganisms as their substrate doesn't require only chemical properties of plastic but also its physical characteristics like melting point, gas transition temperature, crystallinity and modulus etc. [35].

Many researchers showed their keen interest in the microbial degradation of plastic as many organic and inorganic materials like lignin, starch cellulose and hemicellulose are biodegraded by microbes. Some bacteria present in soil consume polyester polyurethane as solitary source of carbon and nitrogen. Similarly, recent research revealed that many microbes present in mangrove soil culture are capable of biodegradation of plastic in efficient way but at a slow rate [36]. Likewise, bacteria many fungi are also able to degrade plastic by penetrating in the polymer solids. Biodegradation of plasticized polyvinyl plastic in in-situ and ex-situ has been observed through fungal colonization [37]. Microorganisms discharge many enzymes into soil water which start the breakdown of polymers. Microbes secrete Intracellular and extracellular polymerases enzymes which breakdown the complex polymers and results into monomers which are minor and can easily be penetrated into cell wall hence used as the source of carbon and energy and the process is called depolymerization. Furthermore, this process when ends up on the products like carbon dioxide, water or methane then it is known as mineralization [38].

Like many other microbes' bacteria are also a major blessing of nature as they help mankind in many ways specially to get rid from waste. There are almost thirty-nine different soil bacterium species which are capable of degrading the plastic [39]. Plastic is degraded aerobically in wild nature or open environment while anaerobically in landfill and sediments but it is also degraded partly aerobically and partly anaerobically in compost and soil. Carbon dioxide and water are produced in aerobic degradation of plastic while methane is also released in anerobic degradation of plastic [40].

A better solution for the complete degradation of plastics has not yet been formulated. However, to solve this global issue biological mode of polyethylene degradation may be evaluated and developed in the upcoming future. Many microbes hold biodegradation capabilities and can be utilized for the purpose.

In 1991 B. Lee [41] and his team investigated the ability of lignin-degrading microorganisms to attack degradable plastics in pure shake flask culture studies. The degradable plastic used in this study was formed commercially by using the ArcherDaniels-Midland POLYCLEAN masterbatch and contained 6\% starch and prooxidant. The known lignin-degrading bacteria Streptomyces viridosporus T7A, S. badius 252 , and $\mathrm{S}$. setonii $75 \mathrm{Vi} 2$ and fungus Phanerochaete chrysosporium were used in the study. Pro-oxidant activity was enhanced by placing a sheet of plastic into a drying oven at $70^{\circ} \mathrm{C}$ under atmospheric pressure and air for $0,4,8,12,16$, or 20 days. For almost every $70^{\circ} \mathrm{C}$ heat-treated film, the Streptomyces spp. demonstrated a further reduction in percent elongation and polyethylene molecular weight average when compared with the corresponding uninoculated control. All the bacteria showed greater potential for biodegradation but no degradation by the fungus was observed. It was first report which explained bacterial degradation of these oxidized polyethylene in pure culture. 
Microalgae can also take part in the process of plastic degradation. In one of the studies by R V Kumar [42] in 2017, Green algae, blue-green algae and diatoms were isolated from the domestic polyethylene bags. These bags were dumped in the suburban water bodies and studied for its potential on deteriorating or degradating polyethylene. Waste polyethylene bags which were previously dumped were collected from three different sites of (Maduravoyal, Vanagaram and Poonamallee) Chennai, Tamil Nadu, India. Colonized mat of microalgae was isolated from the polyethylene sheets and the most dominant three different groups of microalgae were selected for the biological treatment of LD (low density) and HD (high density) polyethylene sheets. The most leading microalgae were Scenedesmus dimorphus (Green microalga), Anabaena spiroides (blue-green alga) and Navicula pupula (Diatom). The biological treatment of the selected microalgae on the LD and HD polyethylene sheets with their respective culture media showed that the microalgae proliferation was more on the LD than the HD polyethylene sheets followed by the highest percentage $(8.18 \%)$ of degradation, obtained from Anabaena spiroides treatment [42].

Study conducted in 2005 revealed that a thermophilic bacterium Brevibaccillus borstelensis strain 707, which was isolated from soil, was found to degrade the branched low-density polyethylene and used it as a sole carbon source. Incubation of polyethylene with $B$. borstelensis $\left(30\right.$ days, $\left.50^{\circ} \mathrm{C}\right)$ compacted its gravimetric and molecular weights by 11 and $30 \%$ respectively. Brevibaccillus borstelensis also degraded polyethylene in the presence of mannitol [43].

A far easier and less hazardous as well as economical solution to the plastic problem could be found in bacteria, however. After all, it seems you can find bacteria that will eat almost anything. And indeed last year a team of Japanese scientists identified a bacterium existing in the wild that can feed on another common plastic, polyethylene terephthalate, used in the making of soft drinks and water bottles (The Guardian, 2017).

In one of the reports, published in The Guardian, 2017, it was stated that the larvae of greater wax moth (Galleria mellonella) can degrade polyethylene by chewing it off. In an experiment by Bertocchini and her colleagues Paolo Bombelli and Christopher Howe [44], of the University of Cambridge, UK, in 2017 observed what 100 wax moth larvae could do to a typical shopping bag in a 40 minutes experiment. The caterpillars chewed holes through it at the rate of two holes per worm an hour. In a time span of 12 hours, they reduced the mass of plastic by 92 milligrams, the fastest plastic degradation process known so far. Another waxeater, the Indian mealmoth, was found in 2014 to house bacteria in its digestive tract that can break down polyethylene. Galleria might have such gut bacteria as well or may have secreted enzymes for the degradation function. Those bacteria could help to make an ideal solution. They could be brewed up in fermentation vats that would allow the plastics to get dissolved without anyone having to expect for planning breeding the wax moth colonies on larger scale. Alternatively, it might be possible to extract the particular enzymes from the insect gut and put them to work on their own - a kind of concentrate of gastric juices. Those bacteria could provide the ideal solution 


\section{Conclusion}

This review has covered the major concerns about the plastics, their uses, and degradability. It has looked at the disasters caused by the plastic industry in the last few decades. It covers major concerns about ocean plastic pollution and its detrimental effects on the aquatic life and humans. Plastics being persistent pollutant in the environment is mainly due to its molecule's rigidity. Ordinary soil microorganisms don't have the resources for degrading such stubborn pollutant type. These plastics are built up from the hydrocarbon molecules in oil, and ideally, it should return to the oil after we had used them, restoring a valuable substance rather than losing it as a left-over. Chemists around the world have been working long and hard to do that, using special catalysts to induce the chemical reactions and thus degrading polymer chains. But it's tough, and only very recently have they started to see progress. Screening of organisms which degrade polymers, or produce enzymes or enzyme systems that degrade polymers, may prove as ecologically profitable solution in the 21 st century. More research is needed for such organisms and enzymes that hold greater potential for plastics degradation. Moreover, recently insects' larvae have been shown to participate as well in polymer degradation. Emphasis should be on an economical and ecofriendly approach in order to get rid of millions of tons of plastic that lies in the environment unaffected.

Keeping in view the current crisis of accumulating plastic pollution, there should be a Global Convention on Plastic Pollution that incentivizes collaboration between managements, manufacturers, scientists, and citizens. If plastic production isn't circumscribed, plastic pollution will be disastrous and will eventually outweigh fish in oceans. Its impact on the humans is another serious issue which must be addressed and resolved before it's too late. It's time to think about the plastics, banning the single use plastics especially, working on awareness programs, thinking about the recycling and going towards the zero-waste concept.

\section{$5 \quad$ References}

[1] Scott G. Polymers in modern life. Polymers and the Environment. Cambridge, UK: The Royal Society of Chemistry; 1999.

[2] Joel, F.R., Polymer Science \& Technology: Introduction to polymer science, Eds. 3, Pub: Prentice Hall PTR Inc., Upper Saddle River, New Jersey 07458, 1995; p: 4-9.

[3] Seymour RB. Polymer science before\&after 1899: notable developments during the lifetime of Maurtis Dekker. J Macromol Sci Chem 1989; 26:1023-32. https://doi.org/10.1080/ 00222338908052032

[4] Sabir, I., Plastic Industry in Pakistan. http://www.jang.com.pk/thenews/investors/nov2004 index.html, 2004.

[5] Europe, P. (2008). The compelling facts about plastics for 2007. EUPCE/EUPR/EPRO/PlasticsEurope.

[6] Brussels et al., Plastics Europe (2009), Compelling facts about plastics, An analysis of European plastics production, demand and recovery for 2008 . 
[7] Van Franeker, J. A., \& Bell, P. J. (1988). Plastic ingestion by petrels breeding in Antarctica. Marine Pollution Bulletin, 19(12), 672-674. https://doi.org/10.1016/0025-326X(88)90388-8

[8] Law, K. L. (2017). Plastics in the marine environment. Annual review of marine science, 9 , 205-229. https://doi.org/10.1146/annurev-marine-010816-060409

[9] Thompson, R. C., Moore, C. J., Vom Saal, F. S., \& Swan, S. H. (2009). Plastics, the environment and human health: current consensus and future trends. Philosophical Transactions of the Royal Society B: Biological Sciences, 364(1526), 2153-2166. https://doi.org/10.1098/rstb.2009.0053

[10] Rochman, C. M., Browne, M. A., Halpern, B. S., Hentschel, B. T., Hoh, E., Karapanagioti, H. K.,\& Thompson, R. C. (2013). Policy: Classify plastic waste as hazardous. Nature, 494(7436), 169. https://doi.org/10.1038/494169a

[11] Jambeck, J. R., Geyer, R., Wilcox, C., Siegler, T. R., Perryman, M., Andrady, A., \& Law, K. L. (2015). Plastic waste inputs from land into the ocean. Science, 347(6223), 768-771. https://doi.org/10.1126/science.1260352

[12] Al-Salem, S. M., Lettieri, P., \& Baeyens, J. (2009). Recycling and recovery routes of plastic solid waste (PSW): A review. Waste management, 29(10), 2625-2643. https://doi.org/10.1016/j.wasman.2009.06.004

[13] Hopewell, J., Dvorak, R., \& Kosior, E. (2009). Plastics recycling: challenges and opportunities. Philosophical Transactions of the Royal Society B: Biological Sciences, 364(1526), 2115-2126. https://doi.org/10.1098/rstb.2008.0311

[14] Quayle, D. V. (1992). Plastics in the marine environment: problems and solutions. Chemistry and Ecology, 6(1-4), 69-78. https://doi.org/10.1080/02757549208035263

[15] Wilber, R. J. (1987). Plastic in the North Atlantic. Oceanus, 30(3), 61-68.

[16] Goldberg, E.D. (1995). The health of the oceans - a 1994 update. Chemical Ecology 10, 3-8. https://doi.org/10.1080/02757549508035325

[17] Robards, M. D., Piatt, J. F., \& Wohl, K. D. (1995). Increasing frequency of plastic particles ingested by seabirds in the subarctic North Pacific. Marine Pollution Bulletin, 30(2), 151-157. https://doi.org/10.1016/0025-326X(94)00121-O

[18] Blight, L. K., \& Burger, A. E. (1997). Occurrence of plastic particles in seabirds from the eastern North Pacific. Marine Pollution Bulletin, 34(5), 323-325. https://doi.org/10.1016/S0025-326X(96)00095-1

[19] Browne, M. A., Dissanayake, A., Galloway, T. S., Lowe, D. M., \& Thompson, R. C. (2008). Ingested microscopic plastic translocates to the circulatory system of the mussel, Mytilus edulis (L.). Environmental science \& technology, 42(13), 5026-5031. https://doi.org/10.1021/es800249a

[20] Thompson, R. C., Olsen, Y., Mitchell, R. P., Davis, A., Rowland, S. J., John, A. W., \& Russell, A. E. (2004). Lost at sea: where is all the plastic? Science, 304(5672), 838-838. https://doi.org/10.1126/science.1094559

[21] Moore, C. J., Moore, S. L., Leecaster, M. K., \& Weisberg, S. B. (2001). A comparison of plastic and plankton in the North Pacific central gyre. Marine pollution bulletin, 42(12), 1297-1300. https://doi.org/10.1016/S0025-326X(01)00114-X

[22] Eriksson, C., \& Burton, H. (2003). Origins and biological accumulation of small plastic particles in fur seals from Macquarie Island. AMBIO: A Journal of the Human Environment, 32(6), 380-385. https://doi.org/10.1579/0044-7447-32.6.380

[23] Barnes, D. K., Galgani, F., Thompson, R. C., \& Barlaz, M. (2009). Accumulation and fragmentation of plastic debris in global environments. Philosophical Transactions of the Royal Society B: Biological Sciences, 364(1526), 1985-1998. https://doi.org/10.1098/rstb.2008.0205

[24] BBC. (2018). Plastic pollution: Images of a global problem. Retrieved from: https://www.bbc.com/news/science-environment-44215881. 
[25] DAWN. (2018). We are temporary beings but the filth we produce will last almost forever. Retreived form: https://www.dawn.com/news/1399496.

[26] Worms. B., et.al, 2017. Annual Review of Environment and Resources. Vol. 42:1-26. https://doi.org/10.1146/annurev-environ-102016-060700

[27] Talsness, C. E., Andrade, A. J., Kuriyama, S. N., Taylor, J. A., \& Vom Saal, F. S. (2009). Components of plastic: experimental studies in animals and relevance for human health. Philosophical Transactions of the Royal Society B: Biological Sciences, 364(1526), 20792096. https://doi.org/10.1098/rstb.2008.0281

[28] Swan, S. H., Main, K. M., Liu, F., Stewart, S. L., Kruse, R. L., Calafat, A. M., \& Teague, J. L. (2005). Decrease in anogenital distance among male infants with prenatal phthalate exposure. Environmental health perspectives, 113(8), 1056-1061. https://doi.org/10.1289/ehp8100

[29] Lang, I. A., Galloway, T. S., Scarlett, A., Henley, W. E., Depledge, M., Wallace, R. B., \& Melzer, D. (2008). Association of urinary bisphenol A concentration with medical disorders and laboratory abnormalities in adults. Jama, 300(11), 1303-1310.

https://doi.org/10.1001/jama.300.11.1303

[30] Myers, J. P., vom Saal, F. S., Akingbemi, B. T., Arizono, K., Belcher, S., Colborn, T., . \& Hassold, T. (2008). Why public health agencies cannot depend on good laboratory practices as a criterion for selecting data: the case of bisphenol A. Environmental health perspectives, 117(3), 309-315. https://doi.org/10.1289/ehp.0800173

[31] Adibi, J. J., Perera, F. P., Jedrychowski, W., Camann, D. E., Barr, D., Jacek, R., \& Whyatt, R. M. (2003). Prenatal exposures to phthalates among women in New York City and Krakow, Poland. Environmental health perspectives, 111(14), 1719-1722. https://doi.org/10.1289/ehp.6235

[32] Rudel, R. A., Camann, D. E., Spengler, J. D., Korn, L. R., \& Brody, J. G. (2003). Phthalates, alkylphenols, pesticides, polybrominated diphenyl ethers, and other endocrine-disrupting compounds in indoor air and dust. Environmental science \& technology, 37(20), 4543-4553. https://doi.org/10.1021/es0264596

[33] Zheng, Y., Yanful, E. K., \& Bassi, A. S. (2005). A review of plastic waste biodegradation. Critical Reviews in Biotechnology, 25(4), 243-250. https://doi.org/10.1080/07388550500346359

[34] Pospisil J, Nespurek S. Highlights in chemistry and physics of polymer stabilization. Macromol Symp 1997; 115:143-63. https://doi.org/10.1002/masy.19971150110

[35] Tokiwa, Y., Calabia, B., Ugwu, C., \& Aiba, S. (2009). Biodegradability of plastics. International journal of molecular sciences, 10(9), 3722-3742. https://doi.org/10.3390/ijms10093722

[36] Nakajima-Kambe, T., Shigeno-Akutsu, Y., Nomura, N., Onuma, F., \& Nakahara, T. (1999). Microbial degradation of polyurethane, polyester polyurethanes and polyether polyurethanes. Applied microbiology and biotechnology, 51(2), 134-140. https://doi.org/10.1007/s002530051373

[37] Webb, J. S., Nixon, M., Eastwood, I. M., Greenhalgh, M., Robson, G. D., \& Handley, P. S. (2000). Fungal colonization and biodeterioration of plasticized polyvinyl chloride. Applied and environmental microbiology, 66(8), 3194-3200. https://doi.org/10.1128/AEM.66.8.31943200.2000

[38] Dey, U., Mondal, N. K., Das, K., \& Dutta, S. (2012). An approach to polymer degradation through microbes. IOSRPHR, 2, 385-388. https://doi.org/10.9790/3013-0230385388

[39] Suyama, T., Tokiwa, Y., Ouichanpagdee, P., Kanagawa, T., \& Kamagata, Y. (1998). Phylogenetic affiliation of soil bacteria that degrade aliphatic polyesters available commercially as biodegradable plastics. Applied and environmental microbiology, 64(12), 5008-5011. 
[40] Gu, J. D., Ford, T. E., Mitton, D. B., \& Mitchell, R. (2000). Microbial corrosion of metals. The Uhlig Corrosion Handbook. 2nd Edition. New York: Wiley, 915-27.

[41] Lee, B., Pometto, A. L., Fratzke, A., \& Bailey, T. B. (1991). Biodegradation of degradable plastic polyethylene by Phanerochaete and Streptomyces species. Appl. Environ. Microbiol., 57(3), 678-685.

[42] Kumar RV, Kanna GR, Elumalai S (2017) Biodegradation of Polyethylene by Green Photosynthetic Microalgae. J Bioremediat Biodegrad 8:381. doi: 10.4172/2155-6199.1000381 https://doi.org/10.4172/2155-6199.1000381

[43] Hadad, D., Geresh, S., \& Sivan, A. (2005). Biodegradation of polyethylene by the thermophilic bacterium Brevibacillus borstelensis. Journal of applied microbiology, 98(5), 10931100. https://doi.org/10.1111/j.1365-2672.2005.02553.x

[44] Paolo et al., Polyethylene bio-degradation by caterpillars of the wax moth Galleria mellonella. 2017 Volume 27, Issue 8. Pages R292-R293 https://doi.org/10.1016/j.cub.2017.02.060

\section{Authors}

Sidra Hassan works in the Department of Plant and Environmental Protection, PARC Institute of Advanced Studies in Agriculture (PIASA), National Agricultural Research Centre (NARC), Islamabad, Pakistan. Email id: sadra_celal@hotmail.com

Ihsan ul Haq works in the Integrated Pest Management Programme (IPMP), National Agricultural Research Centre (NARC), Islamabad, Pakistan.

Article submitted 2019-03-24. Resubmitted 2019-05-17. Final acceptance 2019-05-13. Final version published as submitted by the authors. 